\title{
Regular User Priority Scheme for Performance Improvement in 4G Network
}

\author{
Pushpa \\ Deptt. Of MCA \\ IEC-C.E.T \\ Plot No. 4, KP-1 \\ Gr. Noida, India
}

\author{
Narendra Singh \\ Deptt. Of I.T \\ S.R.I.M.T \\ Plot No. 48B, KP-3 \\ Gr. Noida, India
}

\author{
Prahlad Singh \\ Deptt. Of MCA \\ IEC-C.E.T \\ Plot No. 4, KP-1 \\ Gr. Noida, India
}

\begin{abstract}
Wireless network are growing rapidly, leading to overloaded systems, unacceptable delays and increasing computational costs due to inefficient channel allocation strategy. Handoff call is more important over new call so it must provide some priority; this is the prime objective of all channel allocation strategy. In this paper we propose regular users priority scheme to better utilization of channel and reduce handover blocking probability. We have analyzed a particular path for several users and assign a symbol for regular, medium and normal users. These symbols are also inserted with other related information of user in HLR. Some channels are reserve for regular and medium users over normal users. Strategy of channel reservation schemes provides priority to regular and medium user over normal user. The aim of proposed scheme will use to increase user loyalty by reducing handover blocking probability. Now-a-days it is important not only to acquire new mobile users for mobile companies but also retain them. We can retain mobile users by providing them good channel facility as described in proposed scheme.
\end{abstract}

\section{Keywords}

Wireless networks, Handoff, Handoff blocking probability, Regular user, channel allocation strategy.

\section{INTRODUCTION}

The wireless communication field is a very fast growing area with the no. of mobile subscribers [4] and their demand for better resources increasing day by day.4G wireless supported to launch by 2010 , but there are several issues faced by researchers in achieving the desired features. Following are key features of $4 \mathrm{G}$ [7].

- Full packet switched network

- Anytime and anywhere communication.

- Unlimited spectrum and its allocation

- Introduce a better system with reduces cost

- Support for multimedia services at low bit transmission cost.

- Increasing the user loyalty

- Proper utilization of radio resources.

Currently, most of research works on handoff issues in $4 \mathrm{G}$ systems focuses on keeping unlimited communications with timely location update or reducing handoff latency and packet loss in IP-based Wireless Network. Now-a-days, when no. of mobile subscriber is increasing, it is also important to increase the customer loyalty. It is also one of the objectives of mobile company's that lead the research of increasing loyalty of mobile subscriber. Mobile company is not only concentrating on increasing their subscribers but also how to retain them. We can increase customer loyalty by providing their customer following services:

- Unlimited channel capacity

- All time connectivity

- Un-Interrupted Communication

Unlimited channel capacity can be provided by the proper utilization of resources as we know that spectrum capacity is limited. No subscribers want to drop his call due to limitation of channel. All subscribers want un-interrupted communication from one cell to another cell. Handoff is a process to move from one cell to other. Handoff call is more important then new call. So it is necessary to manage handoff call rather than new call specifically for old and valuable subscriber. Objective of this paper is to increase customer loyalty.

In this paper we present a scheme to provide better quality of service to old and dedicated subscribers by managing handoffs. Proposed scheme is based on analysis of the movement of users from one cell to another in different timestamp for a particular user in particular time periods and construct a probability transition matrix. Generally user follows a fix route or schedule in his daily life so all the preferable handovers are known.

This paper is composed of 5 sections. Section 1 covers the Introduction. In Sec.2, we describe about the system and Sec-3 outlines the Regular user handoff's schemes. Section 3.1 describes the channel allocation strategy. In Sec. 4, we simulate and compare proposed scheme with existing scheme. Finally we conclude the paper in Sec. 5.

\section{SYSTEM DESCRIPTION}

If a subscriber is working in Delhi and living in Meerut and he uses his vehicle to covered this distance daily. He is a business man and uses his mobile during his journey. He started his journey at 8:00 AM and reaches office at 10:00 AM. Similarly he takes $2 \mathrm{hr}$. in returning at 5:00 PM to 7:00 PM. He follows same path from Meerut-Delhi and Delhi-Meerut daily. Consider following path within cellular architecture. 
Person X, start his journey from cell 1 and completed his journey in cell 7. Following position has been observed (fig. 1) in every 5 minutes during i.e. 8:00 to 10:00 AM.

1-2-3-7-6-1-6-5-1-6-5-4-7 handovers have been observed from above table.1 during each 8:00-10:00 AM in Meerut to Delhi path. Now we will check no. of users who will follow the same handovers in path during these hours. Each user is analyzed upto 90 days. And find following probability of each user to follow the same route from Meerut to Delhi.

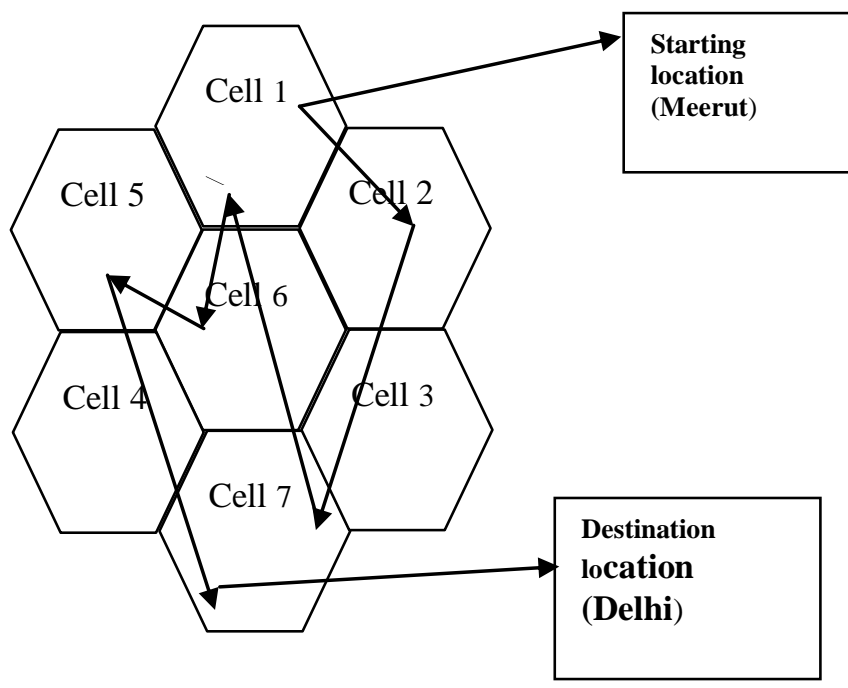

Figure 1: Specific path within cells

Table 1: Represent user location in given time stamp

\begin{tabular}{|l|l|l|l|}
\hline Time & $\begin{array}{l}\text { Location } \\
\text { of cell }\end{array}$ & Time & $\begin{array}{l}\text { Locatio } \\
\text { n of cell }\end{array}$ \\
\hline $8: 00$ & 1 & $9: 05$ & 6 \\
\hline $8: 05$ & 2 & $9: 10$ & 5 \\
\hline $8: 10$ & 2 & $9: 15$ & 5 \\
\hline $8: 15$ & 3 & $9: 20$ & 1 \\
\hline $8: 20$ & 3 & $9: 25$ & 6 \\
\hline $8: 25$ & 3 & $9: 30$ & 5 \\
\hline $8: 30$ & 7 & $9: 35$ & 5 \\
\hline $8: 35$ & 6 & $9: 40$ & 4 \\
\hline $8: 40$ & 6 & $9: 45$ & 4 \\
\hline $8: 45$ & 6 & $9: 50$ & 4 \\
\hline $8: 50$ & 1 & $9: 55$ & 7 \\
\hline $8: 55$ & 6 & $10: 00$ & 7 \\
\hline $9: 00$ & 6 & $10: 05$ & 7 \\
\hline
\end{tabular}

We can compute these probability on the basis of user profile based (UPB) scheme [5]. Average summation of each steady state of each location is the probability of each user.

Table 2: Probability of user to follow a fix path

\begin{tabular}{|l|l|l|}
\hline Sl-No. & $\begin{array}{l}\text { Name of } \\
\text { User }\end{array}$ & Probability \\
\hline 1 & X & $85 \%$ \\
\hline 2 & Y & $76 \%$ \\
\hline 3 & Z & $30 \%$ \\
\hline 4 & A & $15 \%$ \\
\hline 5 & B & $20 \%$ \\
\hline 6 & C & $50 \%$ \\
\hline 7 & D & $60 \%$ \\
\hline 8 & E & $05 \%$ \\
\hline 9 & F & $70 \%$ \\
\hline 10 & G & $45 \%$ \\
\hline
\end{tabular}

Table: 2

Above Table-2 represents probability of covering same path during 8:00-10:00 hr.

\section{REGULAR USER 'S HANDOFF SCHEME}

From above Table 2, we can divide mobile subscribers in three categories.
- Regular user
- Medium user
- $\quad$ Normal user

Regular users are those users whose probability to follow same handover path more than or equal to $65 \%$. Medium users are those users whose probability to follow the same path is less than $65 \%$ and equal to or greater than $50 \%$. Rest of user fall in 'Normal users'. These users are assigned a symbol for identification of their category as shown in Table.3.

Table 3: Types of user according their probability of steady state

\begin{tabular}{|l|l|l|}
\hline User type & Probability Range & Symbol \\
\hline Regular User & $65 \%$ to $100 \%$ & 'R' \\
\hline Medium User & $40 \%$ to $64 \%$ & 'M' \\
\hline Normal User & $1 \%$ to $39 \%$ & 'N' \\
\hline
\end{tabular}


We know that user's information is stored in Home Location Register (HLR).Now we insert a new field ' $R$ ' or ' $M$ ' in data base for each user. ' $\mathrm{N}$ ' symbol is added with normal user. This scheme gives the priority to regular and medium user's handoff over normal user.

\subsection{Channel Allocation Strategy}

If a mobile user wants to talk with other mobile user, then it must get a free channel from the base station. If all the channels are busy, then a new call is considered as 'Block': This kind of blocking is simply known as 'New call Blocking'. In a multi-cell system when the mobile users move from one place to another, during active call, is called as handover [6]. If there is no free channel in new cell the handover call is considered as 'Block': This type of blocking is simply known as 'Handover Blocking'. Handover blocking is more irritating to mobile users than blocking a new call, because no mobile users want to drop his ongoing call. There are various schemes to reduce handoff call dropping probability [1] [3] [2]. So, a handover call usually has a higher priority than a new call for assigning limited resources. In order to decrease the call-dropping rate caused by handover failure, various schemes have been proposed [8] [9] [10] with Guard Channel Strategy (GCS) for Handoff Management. In GCS, total no. of channel is N. There is a threshold value say N' $\left(\mathrm{N}^{\prime}<\mathrm{N}\right)$, if No. of channel is greater than or equal to $\mathrm{N}^{\prime}$ then only handoff call is served all new call is considered as Block. If no. of channel is less N' then all incoming calls are served regardless new or handoff call. If no. of channel is greater than $\mathrm{N}$ then both type of call is considered as block.

Consider following flow chart (figure 2) for channel allocation strategy. In figure.2, symbol Y means 'Yes' and symbol N means 'No'. In our proposed scheme let total no. of channel is $\mathrm{N}$ and no. of channel Reserve for normal handoff is N' where $A<=N^{\prime}<R M$ and total number of channel reserve for regular and medium user's handoff is RM.

Assuming following value for each variable:

$\begin{array}{ll}N=100 & \\ R M=15 & (85-100 \text { channel }) \\ N^{\prime}=25 & (60-84 \text { channel }) \\ A=60 & (0-59 \text { channel })\end{array}$

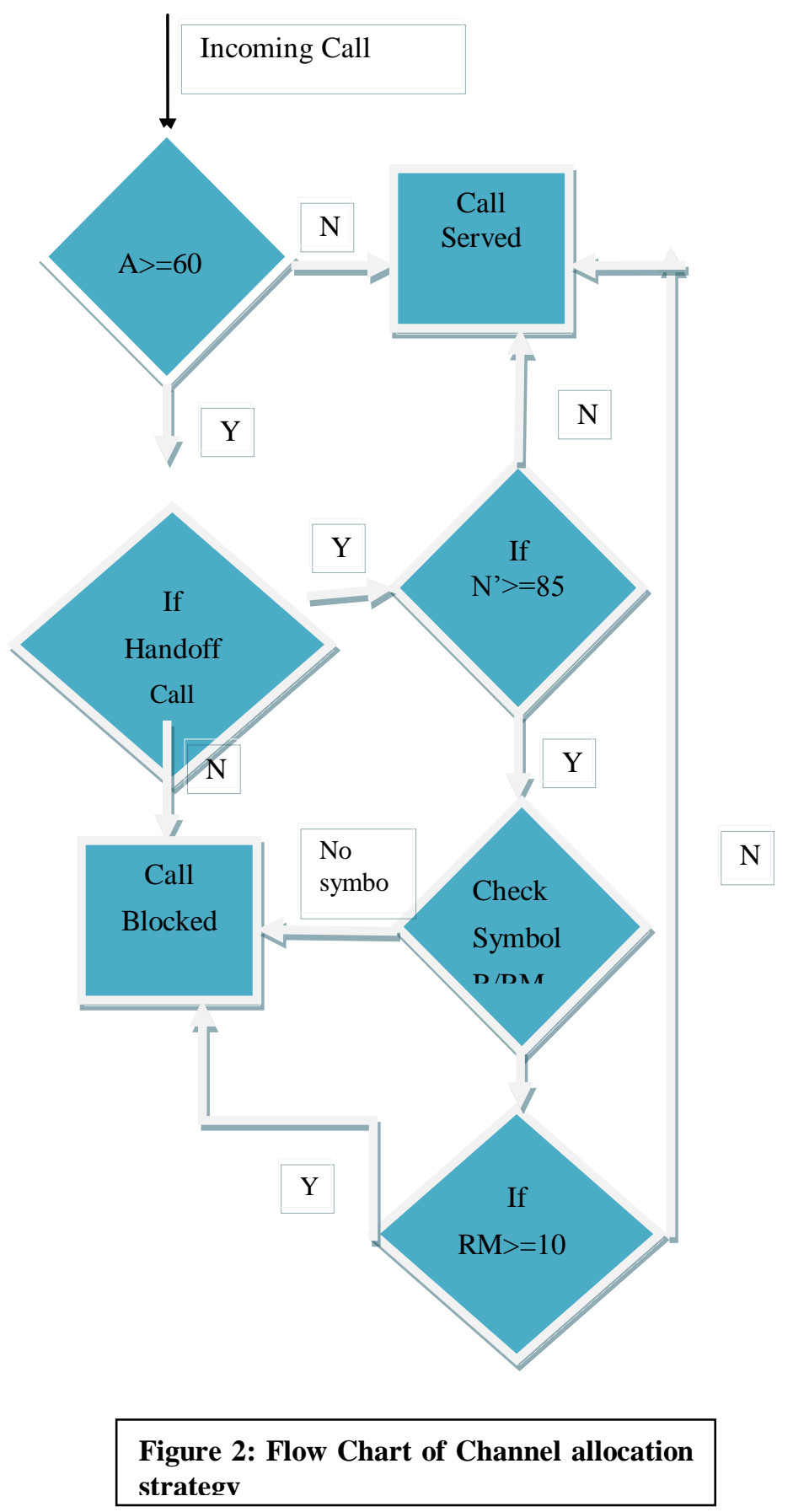

If a call arrives in base station and if no. of channel is less than A then all type of call (new/handoff) is assigned a channel or served. If no. of channel is greater or equal to A then first we have to check whether incoming call is new or handoff. If incoming call is new then it is considered as block otherwise it is served. If no. channel is greater than $M$ then check symbol of user. If user symbol is ' $R$ ' or ' $M$ ' then is served or assign the channel and normal handoff call is considered block. 


\section{SIMULATION \& COMPARISON}

Objective of proposed scheme is to provide quality to old and valuable subscribers. Existing scheme is not differentiating between old and new subscribers. If no channel is reserve for Regular or medium user then all channels $(\mathrm{RM}+\mathrm{N}$ ') is reserve for all type of user's handoff. Let No. of channel is available 15. And following is a queue of incoming user type:

User_Type $=[\mathrm{NH}, \mathrm{RH}, \mathrm{NH}, \mathrm{MH}, \mathrm{NH}, \mathrm{RH}, \mathrm{NH}, \mathrm{RH}$, MH,MH,RH,NH,MH,RH,NH,NH,NH,RH,RH,RH,MH, $\mathrm{MH}, \mathrm{RH}, \mathrm{MH}, \mathrm{RH}]$

$\begin{array}{ll}\text { NH: } & \text { Normal user' Handoff } \\ \text { RH: } & \text { Regular user's Handoff } \\ \text { MH: } & \text { Medium user's Handoff }\end{array}$

It means only first 15 users will be served and rest of users will be treated as blocked.

Block_list= $[\mathrm{NH}, \mathrm{NH}, \mathrm{RH}, \mathrm{RH}, \mathrm{RH}, \mathrm{MH}, \mathrm{MH}, \mathrm{RH}$, $\mathrm{MH}, \mathrm{RH}]$

No. of regular/medium user is blocked $=8$

No. of normal user is blocked $=2$

In our proposed regular user's handoff scheme all 15 channels are dedicated for regular and medium users. So all normal user's handoff is considered as blocked and rest of user' handoff is served.

No. of regular/medium user is blocked $=0$

No. of normal user is blocked $=10$

We have seen maximum regular user and normal users are successfully completed their call without any interruption due to channel shortage. These users are our regular users so we must need to provide better service to them regardless normal or new users.

\section{CONCLUSION}

Major issue of $4 \mathrm{G}$ is not only to provide multimedia support and 24 hour high definition communication but also increasing customer loyalty. It can be increases by using regular user's priority scheme. Specific path is analyzed for various users and if a user is following same path more than $40 \%$ then assign an appropriate symbol R, M or N. These users provide priority over normal users. RM channels are reserved for Regular or Medium type of user. This scheme will definitely increase handoff blocking probability for normal users but provide a better quality to our regular or prospective users.

\section{REFERENCES}

[1] M.H. Ahmed. 2005 Call admission control in wireless networks: a comprehensive survey. IEEE Communication Surveys and Tutorials, vol. 7, no. 1, pp. 50-69.

[2] Mostafizur Rahman and Attahiru Sule Alfa. 2008 Models for Call Acceptance Based on Handoff Guarantees. R3T 5V6, Canada Received 1 November 2007; Accepted 6 August 2008.

[3] Nasif Ekiz, Tara Salih, Sibel Kucukoner and Keman Fidanboylu, 2005 Overview of handoff techniques in cellular networks. International Journal of Information Technology, vol. 2, no. 3, pp. 132-136.

[4] Padgett J. E, Gunther C. G \& Hattori T. 1995 Overview of Wireless Personal Communications. IEEE Communications Magazine, pp. 28-41.

[5] Pushpa, Amit Sehgal, Rajeev Agrawal. 2010 New Handover Scheme Based on User Profile: A Comparative Study. iccsn, pp.18-21,2010 Second International Conference on Communication Software and Networks.

[6] Q. A. Zeng and D. P. Agrawal, 2002 Handbook of Wireless Networks and Mobile Computing. Chapter 1, pp. 1-25, John Wiley \& Sons, Inc.

[7] Roberts, M L et al. 2006 Evolution of the Air Interface of Cellular Communications Systems toward 4G Realization. IEEE Communications Surveys and Tutorials, 8 (1).

[8] S. Choi, and K.G. Shin. 1998 Predictive and adaptive bandwidth reservation for hand-offs in QoS-sensitive cellular networks", in Proc. ACM SIGCOMM, pp. 155-166.

[9] X. Luo, B. Li, I. L. Thng, Y. Lin, and I. Chlamtac. 2002 An adaptive measured-based preassignment scheme with connection-level QoS support for mobile networks. IEEE Trans. on Wireless Commun., vol. 1, no. 3 , pp. 521-529, Jul.

[10] X. Wu, J. Zheng, E. Regentova, and Y. Jiang. 2007 Analysis of the effect of channel sub-rating in unidirectional call overflow scheme for call admission in hierarchical cellular networks," in Proceedings Vehicular Technology Conference, pp. 1265-1269. 